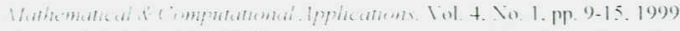

luntatwon for Somotilis Rescardh

\title{
MATHEMATICAL MODEL OF SULPHOMETHYLATION PROCESS OF NONYLPHENOL
}

\author{
Novruz Bashirov \\ Institute of Chemical Additives of Academy of Sciences, \\ Baku, Azerbaijan
}

\begin{abstract}
This paper concerns the development of the mathematical model of sulphomethylation process of nonylphenol based on planning of the experiment. While developing the mathematical model of the process, a method of gross factor experiment (GFE), realizing all possible combinations of the factors chosen, was used by us. By varying four factors on two (minimum and maximum) levels, the experimental values of yields of the product required (sodium sulphate of hydroxynonylbenzyl sulphonic acid), were obtained The coefficients of regression equations $B_{i}$ are calculated by scalar products Then the adequacy of the mathematical model was checked. Thus, a mathematical model of the sulphomethylation process of nonylphenol in the full scale of coordinates was obtained
\end{abstract}

\section{INTRODUCTION}

It is known that sulphonate additives based on sulphonated alkylphenols possess detergentdiapersive, antioxidative and anticorrosion properties. Initial alkylphenol is sulphonated mainly by oleum, concentrated sulphuric acid and sulphuric anhydride. By saponification of alkylphenol sulphonic acids through oxides or hydroxides of alkaline-earth metals, efficient sulphonates are obtained

The main shortcoming of these methods for obtaining the sulphonate additives considered is the application of aggressive reagents (oleum, concentrated sulphuric acid and sulphuric anhydride) as sulphonating agents which lead to environmental contamination. In addition, the sulphonation process promotes the formation of considerable amount $(35-40 \%)$ of acid sludge requiring further utilization. Furthermore, the gelatinous sludge, generated on neutralization step, does not dissolve in organic solvents

To protect the purity of the ambient environment and to eliminate these drawbacks, a new method of manufacturing the multifunctional additives to lubricating oils, based on sulphomethylated alkylphenols (hydroxyalkylbenzyl sulphonic acids), has been developed at the Institute of Chemistry of Additives, Azerbaijan Academy of Sciences [1-3] 


\section{MATHEMATICAL MODELLING}

The sulphonation process of alkylphenol or nonylphenol may schematically be represented as follows
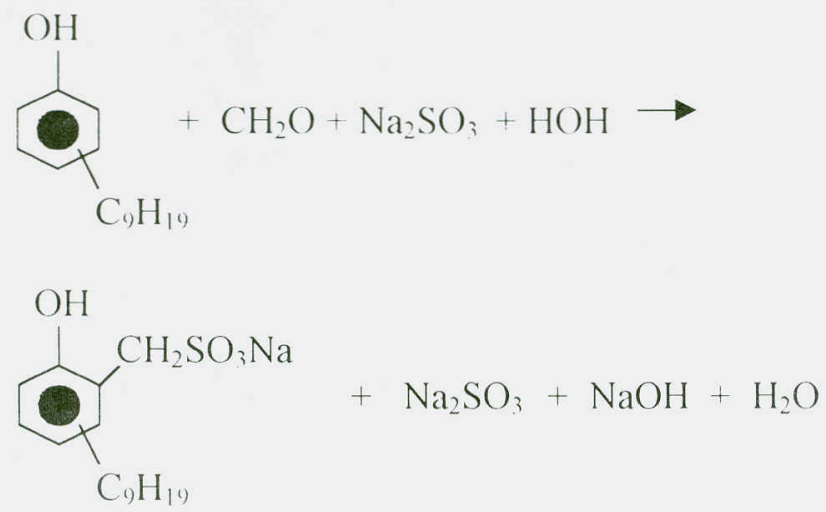

The sodium salt of hydroxynonylbenzyl sulphonic acid (HNBSA) obtained is a starting material for the production of multifunctional additives to lubricants

In developing the mathematical model, the following factors, affecting the process, have been chosen

$Z_{1}$ the amount of $\mathrm{Na}_{2} \mathrm{SO}_{3}, \quad(g)$;

Z. - the amount of formalin, $(\mathrm{mL})$,

Z. - the amount of heptane, $(\mathrm{mL})$;

$Z_{4}-$ the amount of nonylphenol, (g)

The minimum and maximum levels of the factors considered were

$$
\begin{array}{ll}
40<=Z_{1}<=70 & 90<=Z_{:}<=110 \\
30<=Z_{2}<=60 & 40<=Z_{4}<=70
\end{array}
$$

While developing the mathematical model of the process, a method of gross factor experiment (GFE), realizing all possible combinations of the factors chosen, was used. A number of experiments needed $\mathrm{N}$ at GFE is determined by the formula as below.

$$
N=L^{k}
$$

where $\mathrm{L}$ - a number of levels; $k$ - a number of factors.

Considering that $\mathrm{L}=2$ and $\mathrm{k}=4$, a number of experiments needed is

$$
\mathrm{N}=2^{4}=16
$$

By varying four factors on two (minimum and maximum) levels, the experimental values of yields of the product required (sodium sulphate of hydroxynonylbenzyl sulphonic acid), were obtained (Table 1). 
The coefficients of regression equation $\mathrm{B}_{i}$ are calculated by scalar product of $\mathrm{Y}^{\mathrm{u}}$ column on appropriate column $\mathrm{X}_{\mathrm{j}}$, divided by a number of experiments in the matrix of planning $\mathrm{N}$ :

$$
\mathrm{B}_{j}=1 / \mathrm{N}\left(\sum_{i}^{1} X_{\mu} Y_{i}^{e x}\right)
$$

Thus, a following mathematical model of the process in dimensionless co-ordinate system was obtained by us:

$$
\begin{aligned}
Y=105.875-0.375 X_{1}+3 X_{2}+7.8125 X_{3}+1.1875 X_{4}+0.75 X_{1} X_{2}+2.5625 X_{1} X_{i}+ \\
+0.1875 X_{1} X_{4}+1.8125 X_{2} X_{3}+0.6875 X_{2} X_{4}-3.125 X_{3} X_{4}
\end{aligned}
$$

To check the adequacy of the mathematical model obtained, a residual dispersion was calculated by formula as follows

$$
\mathrm{S}_{\mathrm{rem}}^{2}=\mathrm{M} \sum_{Y}^{L_{1}}\left(\bar{Y}_{Y}-Y_{i}^{w}\right)^{2} / F^{2}
$$

where $F=N-k-1$ is a number of degrees of freedom, $N$ - a number of experiments. M a number of parallel experiments; $k$ - a number of factors (in the given case $N=16 ; M=3$; $k=4$ )

For each group of parallel experiments, the selected dispersions were estimated according to formula:

$$
\mathrm{S}_{N}^{2}=\sum_{k}^{M}\left(Y_{i k}-\bar{Y}_{N}\right)^{2} /(M-1)
$$

where $Y_{{ }_{h}}$ - experimental values of the output parameter; $Y_{X}$ - an average value of the output parameter obtained from the results of parallel experiments and calculated by formula:

$$
Y=\sum_{k=1}^{W} Y_{i k} / M
$$

Experimental errors were determined by the formula

$$
\mathrm{S}_{0}=\sum_{i}^{M} \sum_{k=1}^{M}\left(Y_{N k}-\bar{Y}_{1}\right)^{2} / N(M-1)
$$

In the development of the mathematical model, its adequacy was checked by minimizing the differences of squariances of experimental $\left(\mathrm{Y}^{*}\right)$ and estimated $\left(\mathrm{Y}_{\mathrm{x}}{ }^{\mathrm{ust}}\right)$ values. It is considered that the mathematical model adequately describes this particular process in the case of residual dispersion $S^{2}$ rus of the output value $Y^{u x}$, estimated by formula (6) relative to the average experimental values $\mathrm{Y}_{x}$, atatistically does not exceed the errors of the experiment $\mathrm{S}^{2}$,

Tabulated values of Fisher criterion for $\mathrm{P}=0.05$ is $\mathrm{f}_{1}=\mathrm{N}-\mathrm{k}-\mathrm{I}=11 ; \mathrm{f}_{2}=\mathrm{M}-\mathrm{I}=2$. Therefore

$$
F_{1-p}\left(f_{1}, f_{2}\right)=19.41
$$

Fisher criterion was calculated from the formula 


$$
\mathrm{F}_{\mathrm{u}}=\mathrm{S}_{\mathrm{reS}}^{2} / \mathrm{S}^{2}
$$

As $F_{a}=105429 \quad F_{t a h}=19.41$, the mathematical model of the suphomethylation process of nonylphenol in dimensionless system of co-ordinates adequately describes the experiment carried out. Co-ordinates of a centre of a plan in full scale $\left(Z^{\prime \prime}{ }_{1}, Z_{2}^{\prime \prime}, Z^{\prime \prime}, Z^{\prime \prime}{ }_{4}\right)$ and variation units $\left(\Delta Z_{1}, \Delta Z_{2}, \Delta Z_{3}, \Delta Z_{+}\right)$with respect to axes, $Z_{1}, Z_{2}, Z_{\text {s. }} Z_{+}$were calculated as follows

$$
\begin{aligned}
& Z_{1}{ }^{n}=\frac{Z_{1}^{m+4}+Z_{:}^{m n}}{2}=55 \\
& Z_{2}^{\prime \prime}=\frac{Z_{2}^{m a x}+Z^{m m}}{2}=45 \\
& Z_{3}^{0}=\frac{Z_{3}^{\max }+Z_{3}^{\min }}{2}=100 \\
& Z_{4}{ }^{10}=\frac{Z_{+}^{\max }+Z_{+}^{\mathrm{mmx}}}{2}=55 \\
& \Delta Z_{1}=\frac{Z_{1}^{\min }-Z_{1}^{\min }}{2}=1.5 \\
& \Delta Z_{2}=\frac{Z_{z}^{m a x}-Z_{z}}{2}=7.5 \\
& \Delta Z:=\frac{Z^{\max }-Z_{i}^{m+1}}{2}=10 \\
& \Delta Z_{4}=\frac{Z_{4}^{m x}-Z_{4}^{m m}}{2}=15
\end{aligned}
$$

By formula $\quad X_{y}=\frac{Z-Z^{\prime \prime}}{\Delta Z}$ we determine (11)

$$
\begin{aligned}
& x_{1}=\frac{Z-55}{15} \\
& x_{3}=\frac{Z_{3}-100}{10}
\end{aligned}
$$$$
X_{2}=\frac{Z_{2}-45}{7.5}
$$

Then substituting (11) into equation (5), we obtain:

$$
\begin{gathered}
Y=105.875-0.375 \frac{Z_{1}-55}{15}+3 \cdot \frac{Z_{2}-45}{7.5}+7.8125 \frac{Z_{3}-100}{10}+1.1875 \frac{Z_{4}-55}{15} \\
+075 \frac{Z_{1}-55}{15} \frac{Z_{2}-45}{7.5}+0.5625 \frac{Z_{1}-55}{15} \frac{Z_{3}-100}{10}
\end{gathered}
$$$$
+0.1875 \frac{Z_{1}-55}{15} \cdot \frac{Z_{+}-55}{15}+1.8125 \frac{Z_{2}-45}{7.5} \frac{Z_{3}-100}{10}+0.6875 \frac{Z_{2}-45}{7.5} \frac{Z_{+}-55}{15}-
$$ 


$$
-3.125 \frac{Z-100}{10} \frac{Z}{15}
$$

Carrying out all necessary intermediate calculations, at last we obtain:

$$
\begin{gathered}
Y_{1}=7814-1.8792 Z_{1}-1.35972 Z_{2}-101667 Z_{i}+3.02083 Z_{4}+ \\
+0.0033 Z_{1} Z_{2}+0.01708 Z_{1} Z_{-}+0.00083 Z_{1} Z_{4}+0.01208 Z_{2} Z_{3}+ \\
+0.00306 Z_{2} Z_{4}-0.03125 Z_{1} Z_{4}
\end{gathered}
$$

Equation (13) is a mathematical model of the sulphomethylation process of nonylphenol in the full scale of coordinates, the estimated values $\left(\mathrm{Y}_{7}{ }^{\mathrm{sit}}\right)$ of which are given in the last column of the table

Based on the experimental and computed values of the output parameter, the figures of the process are scheduled. As is seen from the figures obtained the mathematical model of the process, developed in the full scale of coordinates, is in good agreement with the experimental data.

Using this mathematical model, it is possible to investigate the process in a wide range of variable parameters and to find optimum conditions for carrying out the process.

\section{METHOD OF SOLUTION}

While planning following the gross factor experiment (GFE), all possible combinations of factors on all chosen levels are realized. Due to optimum location of points in a factor space and linear transformation of coordinates. it is possible to eliminate the defects of a classical regression analysis, in particular the correlation between the coefficients of a regression equation. The choice of a plan is determined by the statement of the problem of investigation and the pecularities of the object. The process of investigation is usually divided into separate steps. Information obtained on each step determines further stategy of the experment So, the possibility of optimal control of the experiment arises. Planning the experiment allows to vary all factors simultaneously and to obtain quantative estimations of the main and interaction effects. The effects of interest are determmed with less emors than using traditional methods of investigation. Ultimately, the application of the plannom methods considerably increases the efficiency of the experiment

While carrying out the experiments only on two level (as in our case) with two values of factors and in so doing during the experiment all possible combinations of $k$ lactors are realized, then the experimental set-up following this plan is known as gross factor experiment of $2^{k}$ type Factors levels represent the borders of the field under investigation according to the given technological parameter.

In the dimensionless coordinate system an upper level is +1 . low level is -1 , the coordinates of a plan's centre are equal to zero and coincide with their origin.

The planning matrix, given in Table I (in a dimensionless system ). possesses the following properties [4]:

$$
\left.\begin{array}{ll}
\sum_{i=1}^{N} X_{m} X_{n}=0, & u \neq j, \overline{0} \overline{0 . k}, \\
\sum_{i=1}^{N} X_{j}=0, & j=1, k, j \neq 0, \\
\sum_{i=1}^{N} X_{j k}^{2}=N, & j=0, k .
\end{array}\right\}
$$




\section{RESULTS AND DISCUSSION}

Following the plan $Z_{1}, Z_{2}, Z_{3}$ and $Z_{4}$ values are affected by $X_{1}, X_{2}, X_{3}$ and $X_{4}$ factors in a dimensionless coordinate system. The values of the output parameter $\mathrm{Y}^{\mathrm{p}}$ were calculated and given in Table 1

Thus, the mathematical model of the process in a dimensionless coordinate system was obtained. Its adequacy was checked by Fisher criterion.

Then, using an equation

$$
X_{j}=\frac{Z_{j}-Z_{j}}{\Delta Z_{j}}
$$

full scale, an equation (13) was derived.

The calculated values of $Y_{x}$ and $Y_{z}$ models are shown in the last two columns of Table I. As can be seen from Table 1, the mathematical model obtained adequately describes the experiment.

By means of this mathematical model, the optimal conditions for carrying out the process will be estabilished

\section{CONCLUSION}

Based on planning the experiment for 4 factors, a mathematical model of sulphomethylation process of nonylphenol was developed

The adequacy of the mathematical model was checked by Fisher criterion and will be used in the optimization process.

\section{REFERENCES}

[1] . A.M. Guliyev, H.R.Hasan-zade, N.H.Abdullayev, A.H.Rzayeva, A.A.Mahmudov. The method for obtaining the antiwear additive to lubricants, USSR Author's Certificate 966550, Bul. Izobret. \#33, 1982.

[2] . N.H.Abdullayev, H.R.Hasan-zade, A.H.Rzayeva, A.A.Mahmudov. Production of multifunctional additives to lubricants, Khimiya i tekhnologiya topliv i masel. $4,17-18,1986$

[3] . N.H.Abdullayev, N.A.Bashirov, N.P.Mustafayev, V.M.Farzaliev, A.A.Mahıudov. A new method for obtaining sulphonate additives to lubricating oils, Tezisy dokladov pervoi natsionalnoy konferensii «Informationnye i upravlyayutshiye sistemy ekologicheskikh problem tekhnologii v neftyanoy, khimicheskoy i neftekhimicheskoy promyshlennosti ( IUS «Ekologiya»), Sumgait, 25, 1992.

[4] S.L.Akhnazarova, V.V.Kafarov. Optimization of Experiment in Chemistry and Chemical Technology. Moscow, 1978, p. 158-165.

[5] A. J. Bondar, Mathematical modelling in Chemical Technology, Kiev, 1973 
Table 1. The results of planning the experiments.

\begin{tabular}{|c|c|c|c|c|c|c|c|c|c|c|c|}
\hline \multirow[t]{2}{*}{ lios } & \multicolumn{4}{|c|}{$\begin{array}{c}\text { Factors in } \\
\text { Dimensionless system }\end{array}$} & \multicolumn{4}{|c|}{ Factors in full scale } & \multicolumn{3}{|c|}{ rield of HNBSA } \\
\hline & $\mathrm{X}_{1}$ & $X_{2}$ & $\mathrm{X}:$ & $\mathrm{X}_{+}$ & $Z$ & $Z_{2}$ & $Z_{3}$ & $Z_{i}$ & $\mathrm{Y}^{-3}$ & $Y^{p}$ & $\mathrm{YF}_{2}$ \\
\hline 1 & 1 & 1 & 1 & 1 & 70 & 60 & 110 & 70 & 117 & 120.375 & 119.5618 \\
\hline 2 & 1 & 1 & 1 & -1 & 70 & 60 & 110 & 40 & 125 & 122.5 & $12+.8118$ \\
\hline 3 & 1 & 1 & -1 & 1 & 70 & 60 & 90 & .70 & 106 & 102.25 & $10+.5622$ \\
\hline 4 & 1 & 1 & -1 & -1 & 70 & 60 & 90 & 40 & 89 & 91.875 & 91.0622 \\
\hline 5 & 1 & -1 & 1 & 1 & 70 & 30 & 110 & 70 & 108 & 107.875 & 107.0618 \\
\hline 6 & 1 & -1 & 1 & -1 & 70 & 30 & 110 & 40 & 113 & 112.75 & 115.0620 \\
\hline 7 & 1 & -1 & -1 & 1 & 70 & 30 & 90 & 70 & 96 & 97 & 99.3122 \\
\hline 8 & 1 & -1 & -1 & -1 & 70 & 30 & 90 & 40 & 89 & 89.375 & 88.5622 \\
\hline 9 & -1 & 1 & 1 & 1 & 40 & 60 & 110 & 70 & 118 & 114.125 & 111.8129 \\
\hline 10 & -1 & 1 & 1 & -1 & 40 & 60 & 110 & 40 & 114 & 117 & 117.8109 \\
\hline 11 & -1 & 1 & -1 & 1 & 40 & 60 & 90 & 70 & 102 & 106.25 & 107.0631 \\
\hline 12 & -1 & 1 & -1 & -1 & 40 & 60 & 90 & 40 & 100 & 96.625 & 94.3131 \\
\hline 13 & -1 & -1 & 1 & 1 & 40 & 30 & 110 & 70 & 104 & 104.622 & 102.3129 \\
\hline 14 & -1 & -1 & 1 & -1 & 40 & 30 & 110 & 40 & 110 & 110.25 & 111.0629 \\
\hline 15 & -1 & -1 & -1 & 1 & 40 & 30 & 90 & 70 & 105 & 104 & 104.8131 \\
\hline 16 & -1 & -1 & -1 & -1 & 40 & 30 & 90 & 40 & 97 & 97.125 & 94.8131 \\
\hline
\end{tabular}

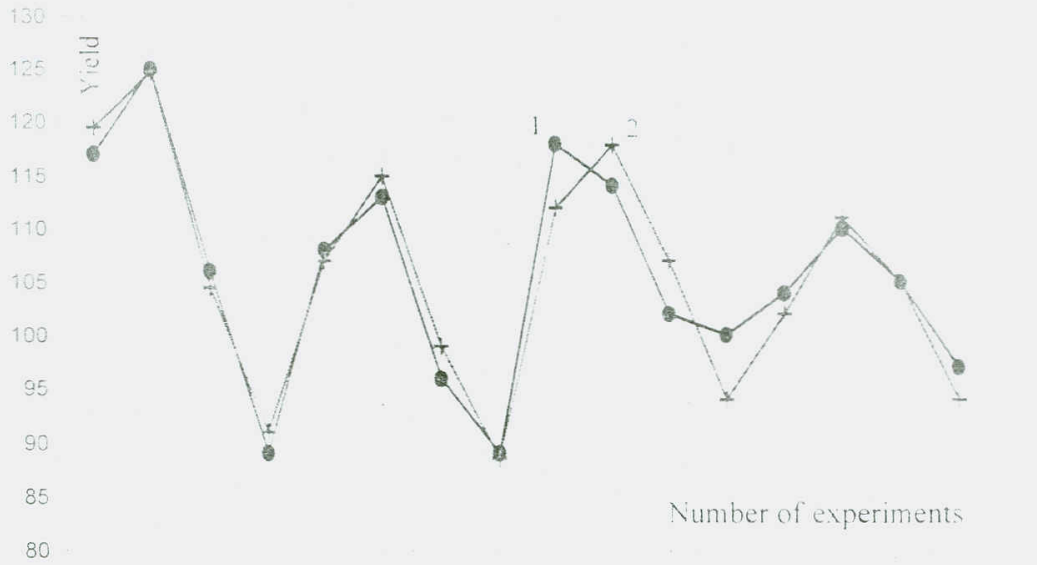

$\begin{array}{llllllllllllllll}1 & 2 & 3 & 4 & 5 & 6 & 7 & 8 & 9 & 10 & 11 & 12 & 13 & 14 & 15 & 16\end{array}$

Figure 1. The sulphometulation process of nonilphenol in affinic coordinate system: 1- by experimental data:

2- by estimating the mathematical model. 